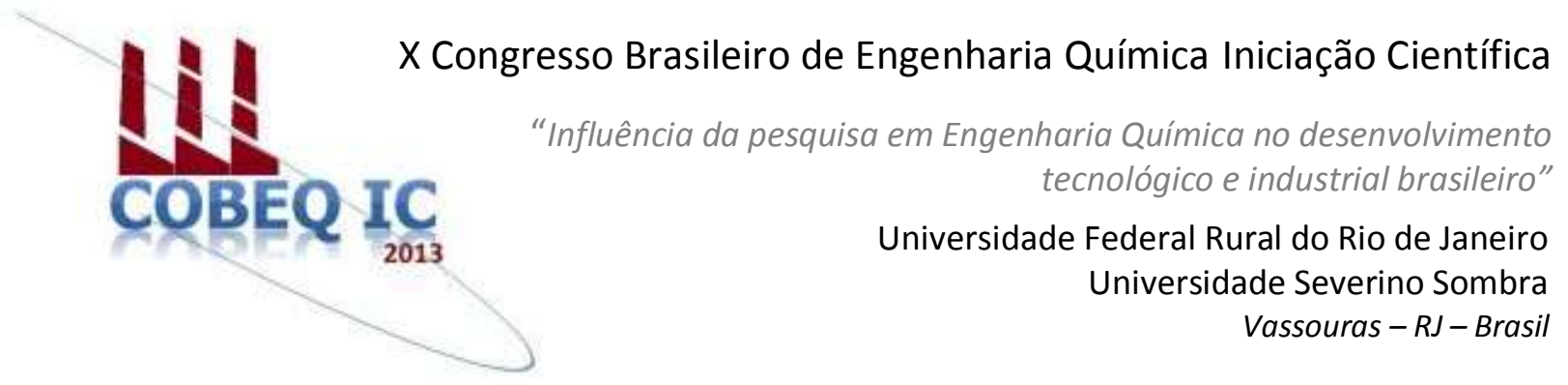

\title{
INVESTIGAÇÃO DE MODELOS SEMI-EMPÍRICOS DE CINÉTICA DE SECAGEM DE PIMENTA-DO-REINO SECA SOB CONVECÇÃO NATURAL
}

\author{
COVRE $^{1}$, V.R.; LIRA ${ }^{2}$, T.S.; BACELOS ${ }^{2}$, M.S. \\ ${ }^{1}$ Bolsista de Iniciação Científica - FAPES ${ }^{2}$ Docente DETEC/CEUNES/UFES \\ Departamento de Engenharia e Tecnologia - Centro Universitário Norte do Espírito Santo \\ Universidade Federal do Espírito Santo \\ Endereço - BR 101 Norte, km 60 - São Mateus, ES - CEP. 29.932-540, ES, \\ email: marcelo.bacelos@ufes.br
}

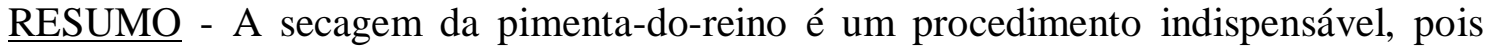
inibe a atividade enzimática e bacteriana, permitindo estender a vida de prateleira, e reduz a massa das amostras, facilitando o transporte. Por outro lado, a secagem exige atenção especial devido ao alto consumo de energia. Atualmente, grande parte da produção nacional é processada utilizando a secagem ao sol. Esta não possibilita obter uma secagem padronizada como ocorre em um secador convencional. Para definir o melhor modelo de secador, é necessário investigar e compreender os efeitos da temperatura e da velocidade do ar sobre a cinética de secagem. Assim, foram propostos modelos empíricos, reportados na literatura, para representar a cinética de secagem. Os modelos foram avaliados aplicando medidas de não linearidade, tais como medidas de curvatura, propostas por Bates e Watts, e vício de Box. O experimento foi conduzido em estufa de convecção natural às temperaturas de $60,70,80,90$ e $100{ }^{\circ} \mathrm{C}$. O experimento permitiu constatar que a taxa de secagem é extremamente dependente da temperatura do ar. $\mathrm{O}$ único modelo que atendeu a todos os requisitos estatísticos foi o modelo de Overhults.
\end{abstract}

Palavras chave: estufa, taxa de secagem, medidas de não linearidade.

\section{INTRODUÇÃO}

A pimenta-do-reino, Piper nigrum, é uma planta nativa da costa do Malabar, Índia, e o seu fruto é uma especiaria famosa devido ao uso como condimento para aperfeiçoar as propriedades organolépticas de alimentos. Embora a pimenta-do-reino tenha sido uma das mais populares especiarias na Europa e América do Norte, seu cultivo é habitualmente praticado apenas em países tropicais. Os maiores produtores mundiais são Vietnã, Brasil, Índia, Indonésia e Malásia.

Com relação à produção nacional, os estados que se destacam são Pará, Espírito Santo e Bahia. Mais da metade da produção nacional é desenvolvida no estado do Pará, contudo no Espírito Santo, o cultivo da pimenta-do-reino é também expressivo, especialmente na região norte do estado, na cidade de São Mateus. 
O procedimento de secagem dos grãos de pimenta possui um papel importante na colheita. A principal vantagem está na redução da atividade de microrganismos e enzimas na decomposição do alimento. Quando a atividade de água do material é reduzido a menos que 0,6 ou 0,7 , os microrganismos ficam inativos. Isto não só permite estender a vida de prateleira da pimenta-do-reino, mas, também, produzir pimenta-do-reino moída, utilizada como tempero.

Além disso, a secagem permite antecipar a colheita, prevenindo possíveis danos à produção devido a condições climáticas. Outro benefício da secagem é a redução de massa e volume, consequentemente, o transporte é facilitado e o custo é reduzido.

Por outro lado, o procedimento de secagem demanda quantidade significativa de energia elétrica, sendo, portanto, necessário um planejamento especial desta etapa. Além disso, a secagem, sem os devidos cuidados, pode causar alterações indesejada na aparência do produto e perda de nutrientes. Apesar desta importância, no Brasil, a maior parte da produção de grãos secos de pimenta-do-reino ainda é processada a partir de técnicas inadequadas, como a secagem em terreiros abertos. Tal técnica torna o processo demorado (4 a 5 dias), não permite obter uma produção padronizada e depende das condições climáticas.

$\mathrm{Na}$ verdade, existe um grande número de secadores comerciais. Devido a essa diversidade, é difícil decidir qual o modelo de secador mais apropriado para um material específico. De acordo com Mujumdar (2007), a seleção do modelo de secador depende das características do material (forma física, efeito tempo-temperatura, encolhimento), produto final (teor de umidade final, qualidade requerida, cor) e consumo de energia.

Para aplicações práticas, ao projetar secadores adequados para o processamento da pimenta-do-reino, é necessário um estudo detalhado sobre a cinética de secagem do grão de pimenta. Tal procedimento investigativo possui papel importante, pois permite compreender como as condições de operação (umidade, velocidade e temperatura do ar) podem afetar o processo. Isto permite, também, decidir o tempo de exposição ao calor, para que o material possa ser seco eficientemente e propor um secador que promova uma secagem rápida e de consumo energético reduzido.

Muitos esforços têm sido concentrados descrevendo o mecanismo do fenômeno de transferência de massa para uma grande variedade de materiais sólidos. Desta forma, procedimentos investigativos, baseados em medidas de não linearidade de modelos semiempíricos, têm sido propostos, para predizer a cinética de secagem (Barrozo et al., 2004).

Atualmente, existem poucas pesquisas sobre a cinética de secagem da pimenta-doreino. Kaensup et al. (1998; 2004) investigaram a cinética de secagem dos grãos de pimenta usando uma técnica combinada de micro-ondas e leito fluidizado.

Como uma contribuição para a secagem da pimenta-do-reino, esta pesquisa tem como objetivo analisar a cinética de secagem dos grãos de pimenta em estufa de convecção natural. Para isso, modelos semi-empíricos, reportados na literatura, que descrevem a cinética de secagem, são aplicados usando estimação de parâmetros pelo método de mínimos quadrados. A adequação dos modelos é avaliada através de métodos não lineares, de acordo com medidas de curvatura de Bates e Watts (1980) e vício de Box (1971).

\section{METODOLOGIA}

\section{Equipamentos}

A secagem é conduzida em estufa de convecção natural (modelo S250, dimensões $60 \times 60 \times 70 \mathrm{~cm}$ ) com controlador de temperatura PID. O sistema de aquecimento consiste em um banco de resistores situados na região inferior da estufa. Tal sistema promove um fluxo de ar por convecção natural dentro da estufa.

\section{Procedimentos Experimentais}

Para a secagem, são usados grãos de pimenta-do-reino verdes cultivados por produtores locais do norte do Espírito Santo. Os grãos de pimenta são colocados em forma redonda de alumínio de $10 \mathrm{~cm}$ de diâmetro. As amostras são preparadas com cerca de $5 \mathrm{~g}$ de massa líquida de pimenta-do-reino. Para 
pesagem, uma balança analítica, com precisão de $0,5 \times 10^{-4} \mathrm{~g}$, foi empregada.

Os experimentos são conduzidos às temperatura de $60,70,80,90$ e $100{ }^{\circ} \mathrm{C}$. A cada 10 minutos, as massas das amostras são pesadas intermitentemente. Ao final da secagem, quando a amostras atingem $o$ equilíbrio (quando a massa das amostras não apresentam variação significativa em três pesagens consecutivas), elas são levadas para a estufa de convecção natural para serem completamente secas. Neste caso, a metodologia de secagem por $24 \mathrm{~h}$ a $105 \pm 3^{\circ} \mathrm{C}$ é usada para definir a massa seca da amostra e, consequentemente, obter o teor de umidade para cada tempo de secagem.

\section{Modelos Semi-Empíricos de Cinética de Secagem}

Baseado na literatura, modelos semiempíricos, descritos na tabela 1, foram escolhidos para análise.

\section{Tabela 1 - Modelos semi-empíricos de cinética de secagem.}

\begin{tabular}{lc}
\hline \multicolumn{1}{c}{ Equações } & Referências \\
\hline $\mathrm{MR}=\exp (-\mathrm{K} \cdot \mathrm{t})$ & Lewis $(1921)$ \\
onde $\mathrm{K}=\mathrm{A} \cdot \exp \left(\frac{-\mathrm{B}}{\mathrm{T}}\right)$ & \\
$\mathrm{MR}=\mathrm{C} \cdot \exp (-\mathrm{K} \cdot \mathrm{t})$ & $\begin{array}{c}\text { Brooker } \text { et } \\
\text { al. }(1974)\end{array}$ \\
onde $\mathrm{K}=\mathrm{A} \cdot \exp \left(\frac{-\mathrm{B}}{\mathrm{T}}\right)$ & Henderson e \\
$\mathrm{MR}=\mathrm{C}\left[\exp (-\mathrm{K} \cdot \mathrm{t})+\frac{\exp (-9 \mathrm{~K} \cdot \mathrm{t})}{9}\right]$ & Henderson \\
onde $\mathrm{K}=\mathrm{A} \cdot \exp \left(\frac{-\mathrm{B}}{\mathrm{T}}\right)$ & Page \\
$\mathrm{MR}=\exp \left(-\mathrm{K} \cdot \mathrm{t}{ }^{\mathrm{C}}\right)$ & $(1949)$ \\
onde $\mathrm{K}=\mathrm{A} \cdot \exp \left(\frac{-\mathrm{B}}{\mathrm{T}}\right)$ & \\
$\mathrm{MR}=\exp \left[-(\mathrm{K} \cdot \mathrm{t})^{\mathrm{C}}\right]$ & Overhults et \\
onde $\mathrm{K}=\exp \left(\mathrm{A}+\frac{\mathrm{B}}{\mathrm{T}}\right)$ & al. $(1973)$ \\
\hline
\end{tabular}

\section{Cálculos da Umidade Adimensional}

$\mathrm{O}$ teor de umidade do material para um dado tempo de secagem pode ser calculado pela expressão seguinte:

$$
M_{(t)}=\frac{W_{(t)}-W_{d r y}}{W_{d r y}}
$$

Onde, $W_{(t)}$ é a massa da amostra em dado tempo $t, W_{d r y}$ é a massa seca da amostra e $M_{(t)}$ é o teor de umidade em base seca em dado tempo $t$.

Consequentemente, para um dado tempo, a umidade adimensional pode ser determinada pela equação:

$$
M R_{(t)}=\frac{M_{(t)}-M_{e q}}{M_{(0)}-M_{e q}}
$$

$M_{(0)}, M_{e q}$ e $M_{(t)}$ são os teores de umidade ao início da secagem, ao equilíbrio e a dado tempo $t$, respectivamente.

\section{Procedimento Estatístico para Análise de Modelos Não lineares}

Muitos algoritmos para calcular a estimativa de mínimos quadrados e muitos métodos de inferência para modelos não lineares são baseados em uma aproximação local linear do modelo. $\mathrm{O}$ efeito desta aproximação é a troca do lócus solução curvado por uma tangente plana, e simultaneamente impõe um sistema de coordenadas uniforme nesta tangente plana. Ambas a eficácia dos algoritmos de mínimos quadrados e a validez das inferências realizadas em relação aos parâmetros do modelo não linear serão afetadas pela aproximação linear do modelo (Bates e Watts, 1980).

Expressões que indicam a adequação da aproximação linear e seus efeitos nas inferências são chamadas medidas de não linearidade. Beale (1960) fez a primeira tentativa de mensurar a não linearidade. Box (1971) avaliou o vício em estimativas não lineares. Bates e Watts (1980) demostraram a relação entre suas medidas e as de Beale, e explicaram porque as medidas de Beale geralmente tendem a subestimar a verdadeira não linearidade.

\section{RESULTADOS E DISCUSSÕES}

\section{Dados Experimentais}

Na figura 1, a umidade adimensional é mostrada como uma função do tempo de secagem para pimenta-do-reino verde, 
parametrizada a temperatura do ar de 60, 70, 80,90 e $100{ }^{\circ} \mathrm{C}$.

Analisando os dados, na figura 1, é possível afirmar que a temperatura afeta o tempo de secagem para as amostrar atingirem o teor de umidade de equilíbrio. Consequentemente, para cada temperatura do ar usada, os dados de cinética de secagem apresentam diferentes inclinações.

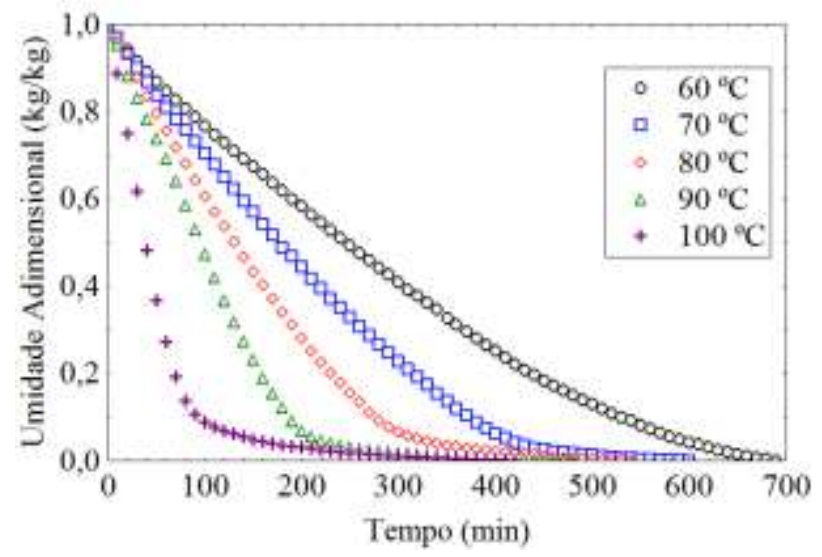

\section{Figura 1 - Umidade adimensional como uma função do tempo de secagem.}

Na figura 2, é feita a descrição da taxa de secagem em função da umidade adimensional, que pode ser geralmente separada em três partes. A primeira, para maiores valores de umidade adimensional (MR>0,6), o aumento da taxa de secagem é observado. Isto ocorre devido ao aquecimento das amostras da temperatura ambiente (aproximadamente $25^{\circ} \mathrm{C}$ ) para a temperatura de trabalho empregada. Por outro lado, apenas quando as temperaturas de 90 e $100{ }^{\circ} \mathrm{C}$ foram usadas, este fenômeno é notado.

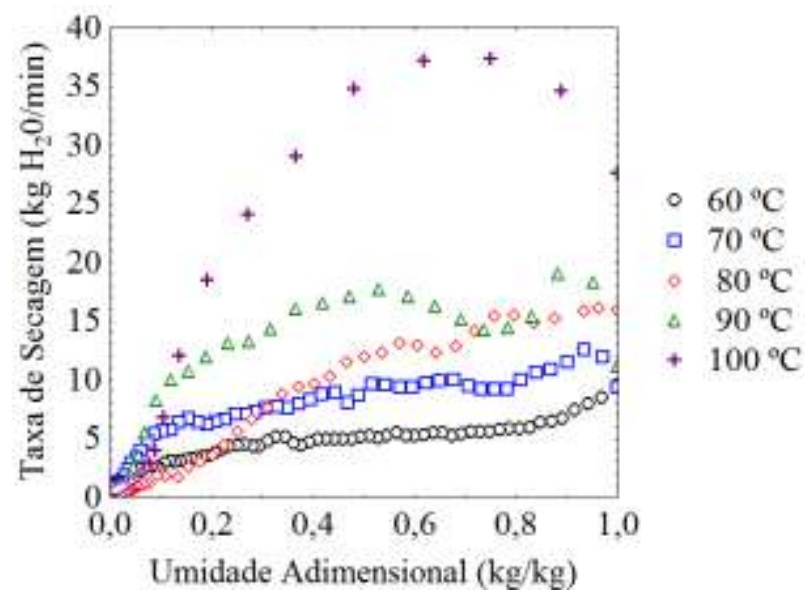

\section{Figura 2 - Taxa de secagem $x$ umidade adimensional.}

A segunda parte ocorre quando a superfície das amostras atinge a temperatura de bulbo úmido e a taxa de secagem apresenta um valor constante. Neste caso, o calor suprido pela convecção por ar natural é responsável sozinho por garantir a evaporação na superfície. Não foram encontrados evidências claras de taxa de secagem a valor constante, isso porque a pimenta-do-reino possui pouca agua livre na superfície.

Em seguida, para baixos valores de umidade adimensional, a taxa de secagem atinge o período decrescente. Esta redução da taxa de secagem ocorre conforme a taxa de difusão não é suficiente para suprir a taxa de evaporação na superfície das amostras. Assim, este passo é controlado pela resistência a difusão.

\section{Estimação dos Parâmetros e Análise Estatística de Modelos Semi-Empíricos}

A estimação dos parâmetros e a análise estatística não linear da adequação para cada modelo semi-empírico são mostradas na tabela 2. O parâmetro A apresenta um maior valor de desvio padrão (entre 30 e $40 \%$ do valor do parâmetro) para todos os modelos, exceto o modelo de Overhults. Isto indica um problema com a estimação do parâmetro A.

Além disso, analisando os dados na tabela 2, o coeficiente de determinação indica que os melhores modelos de acordo com os efeitos intrínsecos são os modelos de Page e de Overhults. Entretanto, a estimativa não apresenta informação suficiente para escolher o melhor modelo não linear para ser aplicado, pois não leva em consideração o efeito paramétrico.

Baseado nas medidas de não linearidade, para um modelo ser considerado apropriado para descrever a cinética de secagem, é necessário ter um vício (para cada parâmetro) e medidas de curvatura (intrínsecas e paramétricas) abaixo de $1 \%$ e $\frac{1}{2} \sqrt{\mathrm{F}}$, respectivamente. $\mathrm{Na}$ tabela 2 , pode-se observar que a curvatura intrínseca e vício de box percentual para os parâmetros B e C são apropriados para todos os modelos. Contudo, apenas a equação de Overhults apresenta vício 
percentual do parâmetro A abaixo de $1 \%$ e adequado valor de curvatura paramétrica. Este fato ocorre devido à reparametrização da constante de secagem, $K$, na equação de Overhults. Assim, para descrever a cinética de

Tabela 2 - Valores estimados dos parâmetros e análise estatística para cada modelo semi-

\begin{tabular}{|c|c|c|c|c|c|c|c|}
\hline Equação & $\begin{array}{l}\text { Coeficiente de } \\
\text { Correlação }\end{array}$ & $\begin{array}{l}\text { Curvatura } \\
\text { Intrínseca }\end{array}$ & $\begin{array}{c}\text { Curvatura } \\
\text { Paramétrica }\end{array}$ & Parâmetros & $\begin{array}{c}\text { Valor } \\
\text { Estimado }\end{array}$ & $\begin{array}{c}\text { Desvio } \\
\text { Padrão }\end{array}$ & $\begin{array}{l}\text { Vício de } \\
\text { Box }(\%)\end{array}$ \\
\hline \multirow{2}{*}{ Lewis* } & \multirow{2}{*}{0,9572} & \multirow{2}{*}{0,0139} & \multirow{2}{*}{15,4403} & $\mathrm{~A}$ & 81,31 & 32,80 & 8,2962 \\
\hline & & & & B & 4738,35 & 139,56 & 0,0110 \\
\hline \multirow{3}{*}{$\begin{array}{l}\text { Brooker } \\
\text { et al.** }\end{array}$} & \multirow{3}{*}{0,9646} & \multirow{3}{*}{0,0397} & \multirow{3}{*}{16,3414} & A & 79,70 & 27,67 & 6,1865 \\
\hline & & & & B & 4702,11 & 120,11 & 0,0091 \\
\hline & & & & $\mathrm{C}$ & 1,09 & 0,01 & 0,0089 \\
\hline \multirow{4}{*}{$\begin{array}{l}\text { Henderson e } \\
\text { Henderson** }\end{array}$} & \multirow{4}{*}{0,9567} & \multirow{4}{*}{0,0439} & \multirow{3}{*}{18,4188} & A & 78,39 & 30,84 & 7,8787 \\
\hline & & & & B & 4711,95 & 136,21 & 0,0121 \\
\hline & & & & $\mathrm{C}$ & 1,04 & 0,01 & 0,0104 \\
\hline & & & \multirow{3}{*}{16,1436} & A & 273,99 & 89,41 & 5,7327 \\
\hline \multirow[t]{2}{*}{ Page** } & \multirow[t]{2}{*}{0,9801} & \multirow[t]{2}{*}{0,0419} & & B & 6385,72 & 154,61 & 0,0373 \\
\hline & & & & $\mathrm{C}$ & 1,37 & 0,02 & 0,0340 \\
\hline \multirow{3}{*}{$\begin{array}{l}\text { Overhults } \\
\text { et al.** }\end{array}$} & \multirow{3}{*}{0,9801} & \multirow{3}{*}{0,0413} & \multirow{3}{*}{0,0394} & A & 4,08 & 0,23 & 0,0149 \\
\hline & & & & B & $-4643,63$ & 79,05 & 0,0042 \\
\hline & & & & $\mathrm{C}$ & 1,38 & 0,02 & 0,0331 \\
\hline
\end{tabular}

secagem da pimenta-do-reino, o modelo de Overhults ajusta os dados melhor.

\section{empírico.}

$* \frac{1}{2} \sqrt{\mathrm{F}(2 ; 276 ; 0,95)}=0,287$

\section{Superfície de Resposta}

$\mathrm{Na}$ figura 3 são apresentadas as superfícies referentes aos valores experimentais e simulados da umidade adimensional experimental e simulada (superfície de resposta para o modelo de Overhults) como uma função do tempo de secagem e da temperatura do ar para secagem por convecção natural. Em adição, a análise dos dados na figura 3 evidencia claramente o efeito da temperatura na cinética de secagem.

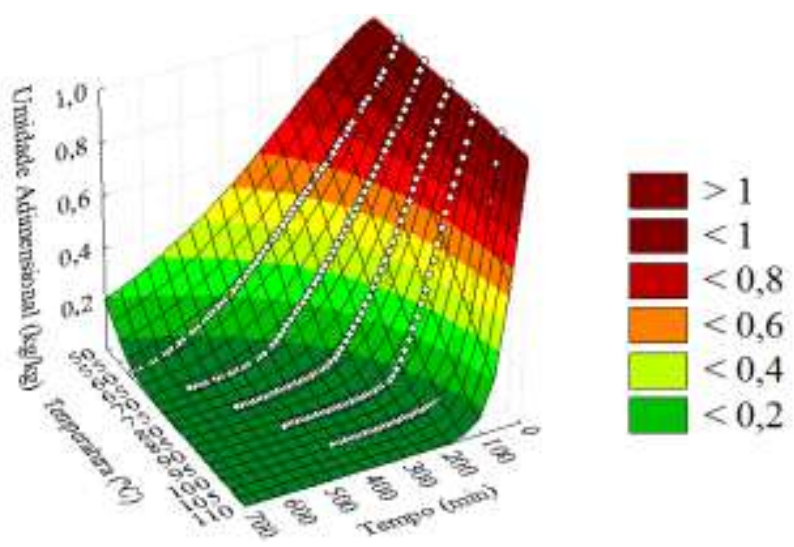

Figura 3 - Superfície de resposta para Overhults apresentando a umidade

$* * \frac{1}{2} \sqrt{\mathrm{F}(3 ; 275 ; 0,95)}=0,308$

\section{adimensional como uma função do tempo de secagem e da temperatura do ar.}

\section{CONCLUSÕES}

Através da análise dos dados da secagem por convecção natural, pode-se observar que a secagem da pimenta-do-reino ocorre em taxa decrescente e, portanto, é controlada principalmente pela resistência a difusão. Assim, a temperatura do ar apresenta efeito importante na cinética de secagem.

Aplicando medidas de não linearidade, o modelo de Overhults ajusta melhor os dados experimentais de secagem.

\section{NOMENCLATURA}

A Parâmetro de modelo semi-empírico

B Parâmetro de modelo semi-empírico [K]

C Parâmetro de modelo semi-empírico

F Valor da distribuição de Fisher

K Constante de secagem

M Teor de umidade $[\mathrm{kg} / \mathrm{kg}]$

MR Umidade Adimensional

$\mathrm{t}$ Tempo [s]

$\mathrm{T}$ Temperatura [K] 


\section{REFERÊNCIAS}

BATES, D.M.; WATTS， D.G. (1980) "Relative Curvature Measures of Nonlinearity" J.R. Statist. Soc. B, 42: 125.

BARROZO, M.A.S.; SARTORI, D.J.M.; FREIRE, J.T. (2004) "A Study of the Statistical Discrimination of the Drying Kinetics Equation" Trans IChemE, 82: 219-225.

BEALE, E.M.L. (1960) "Confidence Regions in Nonlinear Estimation" J.R. Statist. Soc. B, 22: 41-76.

BOX, M.J. (1971) "Bias in Nonlinear Estimation" J.R. Statist. Soc. B, 33: 171201.

BROOKER, D.B.; BAKKER-ARKEMA F.W.; HALL, C.W. (1974) "Drying Cereal Grains" The Avi Publish Company, Inc.: Westport.

HENDERSON, J.M.; HENDERSON, S.M. (1968) "A Computacional Procedure for Deep-Bed Drying Analysis" J. Agric. Eng. Res., 13: 87-95.

KAENSUP, W.; WONGWISE, S. (2004) "Combined Microwave/Fluidized Bed Drying of Fresh Peppercorns" Drying Technology, 22: 779-794.

KAENSUP, W.; WONGWISE, S.; CHUTIMA, S. (1998) "Drying of Pepper Seeds Using a Combined Microwave/Fluidized Bed Dryer" Drying Technology, 16: 853-862.

LEWIS, W.K. (1921) "The Rate of Drying of Solids Materials" Ind. Eng. Chem., 13: 427-432.

MUJUMDAR, A.S. (2007) "Principles, Classification, and Selection of Dryers". Handbook of Industrial Drying. Editora CRC Press, Nova York.

OVERHULTS, D.G.; WHITE, G.M.; HAMILTON, H.E.; ROSS, I.J. (1973) "Drying Soybeans with Heated Air" Trans. of the ASAE, 112-113.

PAGE, G.E. (1949) Factors Influencing the Maximum Rates of Air Drying Shelled
Corn in Thin-Layer, Purdue University, Indiana (dissertação de mestrado).

\section{AGRADECIMENTOS}

Os autores agradecem a FAPES, CAPES e CNPQ pelo suporte financeiro que permitiu conduzir a presente pesquisa. 